arterial circulation of the kidney does away with the blood current which normally, flows away from the region of the tubules, and, this being the case, the venous blood of the renal cardinal meshwork, encountering no resistance, is enabled to penetrate to the tubule plexus, carrying with it the injected diuretics which cause the secretion observed. There is no reason why the secretion should not occur under these abnormal conditions. The tubule epithelium is well supplied with oxygen, the veins are gorged with impure blood, and in experiments in which at all large secretions were obtained the pressure was artificially raised by forced injection or otherwise.

It is easy, then, to account for the secretion obtained by the investigators named, and at the same time to believe that the venous blood takes no share in the formation of the kidney secretion under normal conditions.

It has always surprised me, speaking as an outsider, that physiologists have so readily assumed that they possess in the frog and other animals with "portal " kidneys so many convenient anatomical contrivances in which the glomeruli and the renal tubules are supplied by separate vessels. It is true that the renal cardinal meshwork is continuous with the blood plexus surrounding the tubules, but surely it is very unsafe to assume from this one fact that the venous blood is used by the tubules for secretory purposes. Another equally patent fact, that the similar tubules of mammals employ arterial blood, should suffice to cast doubt on the assumption. And when we recall to mind the statements of Hyrtl (Wiener Akad. SB., xlvii. 1863) and Vialleton (C. $\dot{R}$. Hebdom. Séances Soc. Biol. Paris, liv., 1902), among others, that in those "portal" kidneys in which the vascularisation has been histologically examined, viz. those of the frog and certain sharks, the renal cardinal meshwork is structurally distinguishable from the tubule plexus (the former consisting essentially of large channels putting the post-renal vein into communication with the post-caval, and the latter consisting of capillaries which open into the channels), tisere is still more reason for supposing that the flow of blood is from the tubule plexus into the renal cardinal meshwork, and not in the contrary direction. The numerous experiments which have been based on the aforesaid assumption have, I should imagine, given rise to incorrect ideas as to the normal functions of the urinary tubules.

If I needed any additional physiological evidence in support of my contention that the post-renal vein has nothing to do with the vascular plexus of the urinary tubule, i.e. does not supply the kidney for excretory purposes, I find it to hand in the recently issued British Association Report for 1906, York. In a report on "The "Metabolic Balance Sheet of the Individual Tissues," p. 427, it is shown to be exceedingly probable, by the relative amounts of oxygen used up by the kidney tissue of a frog and a mammal respectively, that the "renal-portal" vein of the frog bears a very different relation to the kidney tubules as compared with that of the renal vein of mammals-which is the conclusion I am maintaining. It is further stated that "when the same kidney is perfused at different times through the aorta and through the renal-portal system, there is a greater consumption of oxygen in the former case than in the latter (double to treble in four experiments)." If we assume what is generally held to be a well-established fact, viz. that the kidney-tubule epithelium plays quite as important a part in kidney secretion as the glomerular epithelium, then it is difficult to understand, on the portal theory of the kidney, why the quantity of oxygen absorbed by the kidney tubule is totally out of proportion to the work done by it. Obviously the only rational conclusion to draw is that in the above experiment the oxygen perfused through the "renal-portal" vein did not come into contact with the tubule.

To sum up, I think I may say that I have clearly shown that the recent work of Bainbridge, Beddard, and Cullis does not disprove my original contention that the renal cardinal meshwork is, under natural conditions, nonexcretory, that, in short, the so-called " renal-portal", vein does not supply the renal tubules, as physiologists commonly assume, and that, in consequence, experiments based on this assumption are liable to give rise to misleading ideas.

W. WOOdLAND.

\section{Mendelism and Biometry.}

IN the striking and suggestive review of Mr. Punnett's work on "Mendelism," in Nature of May 23, the reviewer cites, without naming the author, a view expressed by $\mathrm{Mr}$. A. D. Darbishire (Manchester Memoirs, 1906) to the effect that " the Mendelian deals with units and the biometrician with masses," and states that this idea, "though plausible, is based on a fallacy," for " the Mendelian's units are the biometrician's masses, except when the latter exceeds his limits and includes within his masses more than one such unit."

I have no doubt that Mr. Darbishire read the review with as much enjoyment as myself, but it seems to me that his statement of the case is dismissed with scarcely sufficient consideration. The reviewer's points, if I understand aright, are two:-(I) that Mendel's laws (by which he seems to mean, not merely the law of segregation, but the laws of observed proportions) are really mass-laws and not laws of the individual; (2) that the biometrician's masses are the masses to which Mendel's laws apply. But surely (I) Mendel's laws are based on definite conceptions as to the germ-cells of the individual-and that is the important point-and are true of the individual to a degree of approximation which is the higher the greater the number of offspring (quite a high degree in such a case as Mr. Lock's maize). Further, (2) if the "Mendelian's units " were the "biometrician's masses," there should be inheritance of individual variations, within each of two races $\mathrm{A}$ and $a$, for any character to which Mendel's laws applied on crossing those races; for inheritance of individual variations is what the biometrician has observed for nearly all characters in his masses.

I indicated the importance of an investigation on this point some time ago (New Phytologist, i., 234)-for it is almost a fundamental question whether a single determinant, such as nuay be assumed to exist for a unit Mendelian character, is or is not capable of variation from individual to individual-but I am not aware that any such investigation has been made. The reviewer's assumption may, therefore, be true, but it is unproven, and theories at present in the field (Pearson, Phil. Trans., 1504; Yule, Conference on Genetics, 1906) are based on the npposite assumption, viz. that heritable individual variations are due to the character concerned being determined by $n$ allelomorphic couplets, and not by one. If this be true, the "biometrician's masses" are precisely masses to which Mendel's laws, in their simplest form, do not apply.

The question referred to above, whether a unit Mendelian character exhibits heritable individual variations or no, seems to be one that urgently calls for experimental investigation. G. UDNY YULE.

Mr. Yule is probably right. The question is this: Is the inheritance which the biometrician always finds within the limits of his masses due to the fact that he is dealing with a large number of Mendelian units, or that he is measuring the intensity of heredity within such a unit?

If the former, Mr. Yule is right in saying that I criticised the view expressed by Mr. Darbishire unjustly. If the latter, the mass of the biometrician is the unit of the Mendelian. But before we can give an answer to this question we must know, as Mr. Yule points out, whether there is inheritance of fluctuating variations within the limits of a single Mendelian character such as " tall," in peas. If we may argue from stature in man to stature in peas, we should compare the character tall (or normal) in peas to tall (or normal) in man, and dwarf in peas to dwarf in man. We know that there is inheritance within the character tall in man, and, if this analogy is legitimate, we should expect to find it so in peas. If it were, the answer to the question whether the view expressed by Mr. Darbishire were right or not would depend on whether we still cal!ed the character tall the unit or extended the conception of unit to the smallest heritable variation within the category tall.

The Reviewer.

No. I963, voL. 76$]$ 